\title{
Morphological characterization of pre- and peri-implantation in vitro cultured, somatic cell nuclear transfer and in vivo derived ovine embryos
}

\author{
P Tveden-Nyborg, T T Peura ${ }^{1}$, K M Hartwich² ${ }^{2}$ S K Walker ${ }^{2}$ and P Maddox-Hyttel \\ Department of Animal and Veterinary Basic Sciences, Royal Veterinary and Agricultural University, \\ Groennegaardsvej 7, DK-1870 Frederiksberg C, Denmark, ${ }^{1}$ Sydney IVF Ltd, 4 O'Connell Street, Sydney, \\ NSW 2000, Australia and ${ }^{2}$ South Australian Research and Development Institute, Turretfield Research Centre, \\ Rosedale, SA 5350, Australia
}

Correspondence should be addressed to Pernille Tveden-Nyborg; Email: ptn@kvl.dk

\begin{abstract}
The processes of cellular differentiation were studied in somatic cell nuclear transfer (SCNT), in vitro cultured (IVC) and in vivo developed (in vivo) ovine embryos on days 7, 9, 11, 13, 17 and 19. SCNT embryos were constructed from in vitro matured oocytes and granulosa cells, and IVC embryos were produced by in vitro culture of in vivo fertilized zygotes. Most SCNT and IVC embryos were transferred to recipients on day 6 while some remained in culture for day 7 processing. In vivo embryos were collected as zygotes, transferred to intermediate recipients and retransferred to final recipients on day 6 . All embryos were processed for examination by light and transmission electron microscopy or immunohistochemical labelling for alpha-1-fetoprotein and vimentin. Overall, morphological development of in vivo embryos was superior to IVC and SCNT embryos. Day 7 and particularly day 9 IVC and SCNT embryos had impaired hypoblast development, some lacking identifiable inner cell masses. On day 11, only in vivo and IVC embryos had developed an embryonic disc, and gastrulation was evident in half of in vivo embryos and one IVC embryo. By day 13, all in vivo embryos had completed gastrulation whereas IVC and SCNT embryos remained retarded. On days 17 and 19, in vivo embryos had significantly more somites and a more developed allantois than IVC and SCNT embryos. We conclude that IVC and particularly SCNT procedures cause a retardation of embryo development and cell differentiation at days 7-19 of gestation.

Reproduction (2005) 130 681-694
\end{abstract}

\section{Introduction}

Since the birth of the first lamb cloned from an adult somatic cell (Campbell et al. 1996, Wilmut et al. 1997), the technique of somatic cell nuclear transfer (SCNT) has been applied to a wide range of animal species. It is, however, evident that the process is associated with a dramatic loss of embryos and fetuses throughout gestation, with the majority being lost in the first trimester (Hill et al. 2000). In particular, the period of implantation appears to be critical (Wilmut et al. 1997, Cibelli et al. 1998, de Sousa et al. 2001). SCNT embryos display retarded embryonic development and a variety of organ malformations, as well as an increased frequency of the large offspring syndrome (LOS), manifesting itself as increased birth weight and increased gestation length for pregnancies brought to term (Wilson et al. 1995, Young et al. 1998, de Sousa et al. 2001, Chavatte-Palmer et al. 2004). Examinations of placental tissues from SCNT pregnancies have revealed deviant placental vascularization and development, a phenomenon that results in increased occurrence of hydrallantois and the presence of enlarged placentomes (Hill et al. 1999, Heyman et al. 2002). In addition, abnormal placental formation plays a crucial role in the development of LOS and is a major cause of embryo and fetal loss (Hill et al. 2000, Bertolini \& Anderson 2002). The causes of pathological placental development have not been fully elucidated, but numerous studies on gene expression (Daniels et al. 2000, Wrenzycki et al. 2001, 2002, Humpherys et al. 2002) have revealed disproportionate expression patterns in cloned embryos, supporting the hypothesis that epigenetic reprogramming of SCNT embryos is abnormal (Humpherys et al. 2001, Young et al. 2001, Dean et al. 2003, Han et al. 2003, Shi et al. 2003).

Proper placental formation requires several developmental processes. Sheep placentation is chorioallantoic and is initiated with the budding of the allantois from the endoderm of the hind gut. Subsequently, placental 
vascularization is formed by the visceral mesoderm surrounding the allantois. Hence, a proper formation of the germ layers (endoderm, mesoderm and ectoderm) during the process of gastrulation is a key requirement for normal placental development.

In this investigation, we included three experimental groups: in vivo embryos as a control, in vitro cultured (IVC) embryos cultured in a medium supplemented with $20 \%$ human serum in order to provoke embryonic stress leading to LOS changes (Thompson et al. 1995, Walker et al. 1996a), and SCNT embryos.

The present study aimed to examine IVC and SCNT embryos in order to determine whether placental abnormalities previously associated with these procedures may have their origins during differentiation of the germ layers and formation of the allantoic bud. Pre- (days 7, 9, 11 and 13) and peri-implantation (days 17 and 19) ovine embryos produced by in vitro culture or SCNT were compared with in vivo derived embryos. All embryos were submitted to stereo-microscopy, and embryos collected on days 7, 9, 11 and 13 were processed for either transmission electron microscopy (TEM) or immunohistochemical examination of germ layer formation with the markers alpha-1-fetoprotein and vimentin (Maddox-Hyttel et al. 2003).

\section{Materials and Methods \\ Overall experimental design}

Three groups of embryos were analysed: in vivo derived embryos (in vivo embryos), in vivo fertilized but in vitro cultured embryos (IVC embryos), and somatic cell nuclear transfer embryos (SCNT embryos). In vivo and IVC embryos were fixed (see later) on days 7, 9, 11, 13, 17 and 19 after fertilization, and SCNT embryos on the same days after nuclear transfer.

\section{Preparation of ewes}

\section{Donor ewes}

Oestrus was synchronized by the administration of an intravaginal progestagen pessary (flugestone acetate; 45 mg; Laboratorie Pharmaceutique Porges, Paris, France) for 12 days. Superovulation was induced with follicle-stimulating hormone (FSH) $(10 \mathrm{ml}$, i.m.; Folltropin, Vetrepharm, Ontario, Canada) administered in six decreasing does commencing $48 \mathrm{~h}$ before pessary removal and thereafter at 12-h intervals. Pregnant mare serum gonadotrophin (PMSG, $500 \mathrm{IU}$ i.m. Pregnecol; Horizon Technology, North Ryde, NSW, Australia) was administered concurrently with the initial FSH injection. At $12 \mathrm{~h}$ after the final FSH injection, gonadotropin-releasing hormone $(\mathrm{GnRH}, 0.3 \mathrm{ml}$ i.m.; Fertagyl, Intervet International, Boxmeer, Netherlands) was administered. Donors were artificially inseminated directly into the uterine lumen with a laparoscope, with approximately $1 \times 10^{7}$ motile sperm $14 \mathrm{~h}$ after $\mathrm{GnRH}$ treatment. Semen was collected from rams of proven fertility and diluted with PBS containing $5 \%$ heat inactivated sheep serum (HISS). The day of ovulation was designated as day 0 .

\section{Recipient ewes}

Oestrus was synchronized as for donor ewes with a progestagen pessary. PMSG $(0.4 \mathrm{ml} \mathrm{i.m}$.) was administered at the time of pessary removal. All recipients were synchronized within $\pm 12 \mathrm{~h}$ of donor ewes.

\section{Generation of embryos}

All reagents were obtained from Sigma and were of cell culture grade unless otherwise specified.

\section{In vivo embryos}

Twelve ewes were used to generate in vivo embryos. Putative zygotes were recovered from the oviducts of superovulated donors and transferred (10-20 per ewe) directly to the oviducts of synchronized intermediate recipients $(n=2)$. Embryos were subsequently recovered on day 6 , and resultant blastocysts transferred (10-15 per ewe) to final recipients $(n=20)$ for recovery on days $7,9,11,13$, 17 and 19. For recovery of embryos, ewes were killed by a lethal dose of phenobarbitone (Virbac Australia Pty Ltd, Peakhurst, New South Wales, Australia), and the intact reproductive tract was excised. Once each tract had been trimmed of excess tissue, PBS with 5\% HISS was flushed through the uterine horns in a retrograde direction from the uterotubal junction. Fluid passing out through the body of the uterus was collected into $90 \mathrm{~mm}$ Petri dishes. Embryos were identified under a stereo-microscope and fixed as detailed below.

\section{In vitro cultured (IVC) embryos}

Putative zygotes were recovered from superovulated donor ewes and placed directly into pre-equilibrated modified synthetic oviduct fluid (mSOF) medium (Tervit et al. 1972) supplemented with $20 \%$ heat-inactivated human serum (HIHS). Subsequent culture was conducted at $38.5^{\circ} \mathrm{C}$ in a humidified atmosphere of $5 \% \mathrm{O}_{2}, 5 \% \mathrm{CO}_{2}$ and $90 \% \mathrm{~N}_{2}$. On day 6 , the majority of resultant blastocysts were transferred to synchronized recipients $(n=8)$, as described above (10-15 blastocysts per ewe), and subsequently recovered from the reproductive tract on days $9,11,13,17$ and 19 . The remaining blastocysts were cultured to day 7 and then fixed directly from the culture medium.

\section{Somatic cell nuclear transfer (SCNT) embryos}

SCNT embryos were constructed according to previously described protocols, using oocytes from adult ovaries for cytoplast production and adult granulosa cells as karyoplasts (Peura 2003). 


\section{Karyoplast derivation}

Granulosa cells were obtained by removing cumulus cells from immature in vivo sourced oocytes and culturing them to passage 3 in Glasgow's medium (Gibco, Life Technology, Auckland, New Zealand) supplemented with sodium pyruvate, L-glutamine, DMEM, penicillin, streptomycin and $5 \%$ heat-inactivated fetal calf serum (FCS) (CSL, Parkville, Australia). Once cells were 90\% confluent, they were frozen in a 10\% DMSO and 90\% FCS solution in Nunc cryotubes (Nunc, Roskilde, Denmark) at a concentration of approximately 200000 cell $\mathrm{s} / \mathrm{ml}$ and stored in liquid nitrogen. On the day of use, a cryotube of frozen cells was thawed in a $45^{\circ} \mathrm{C}$ water bath, washed with fresh Glasgow's medium and centrifuged (2500 r.p.m., $20 \mathrm{~min}$ ) to remove cryoprotectants. The cell pellet was then resuspended with modified Glasgow's medium and held at $38.5^{\circ} \mathrm{C}$ until used for cell injection (within $1-4 \mathrm{~h}$ ).

\section{Cytoplast production}

Briefly, ovaries were collected from a local slaughterhouse. Follicles of $>2 \mathrm{~mm}$ were aspirated, and the cumulusoocyte-complexes (COCs) were placed in HEPES-buffered TCM-199 (Sigma) supplemented with $2 \%$ HISS and 100 i.u./ml heparin. COCs were washed in and then transferred to four-well plates (Nunc; 25 per well) containing $0.6 \mathrm{ml}$ maturation medium (TCM-199; Sigma) supplemented with $20 \%$ HISS; $5 \mu \mathrm{g} / \mathrm{ml} \mathrm{FSH}, 5 \mu \mathrm{g} / \mathrm{ml}$ luteinizing hormone (LH) and $1 \mu \mathrm{g} / \mathrm{ml}$ oestradiol. The medium was overlaid with mineral oil $(0.3 \mathrm{ml})$, and culture occurred at $38.5^{\circ} \mathrm{C}$ in a humidified atmosphere of $5 \% \mathrm{CO}_{2}$ in air. Cumulus cells were removed from COCs $18 \mathrm{~h}$ later with hyaluronidase (500 i.u./ml) and pipetting. Denuded oocytes were placed in mSOF supplemented with $4 \mathrm{mg} / \mathrm{ml}$ BSA (Gibco Life Technologies) and amino acids at ovine oviduct fluid concentrations (Walker et al. 1996b) until enucleated. As required, groups of oocytes (maximum 20) were incubated in hSOF (HEPESbuffered SOF with $4 \mathrm{mg} / \mathrm{ml}$ BSA) containing $7.5 \mu \mathrm{g} / \mathrm{ml}$ cytochalasin B and $5 \mu \mathrm{g} / \mathrm{ml}$ Hoechst (33342) for $5 \mathrm{~min}$ and then placed in enucleation medium (hSOF containing $7.5 \mu \mathrm{g} / \mathrm{ml}$ cytochalasin B). Enucleation involved the removal of a minimal amount of cytoplasm from the area directly underlying the polar body. All material removed from the oocyte was viewed under UV light to confirm that the metaphase II plate had been removed. After enucleation, the karyoplast was immediately injected into the perivitelline space through the enucleation hole in the zona pellucida. After reconstruction, cytoplast-karyoplast couplets were held in culture media until the time of fusion.

\section{Fusion}

Nuclear fusion was performed with a Genaust Fusion Machine (Genetics Australia, Bacchus Marsh, Australia) in a mannitol fusion medium $(0.3 \mathrm{M}$ mannitol, $0.05 \mathrm{mM}$ $\mathrm{CaCl}_{2}$ and $0.1 \mathrm{mM} \mathrm{MgSO}$ ). The manipulation chamber comprised two parallel, $0.1 \mathrm{~mm}$ diameter platinum wires separated by $0.2 \mathrm{~mm}$. An AC-alignment pulse of $400 \mathrm{kHz}$ and $10 \mathrm{~V}$ was followed by two DC pulses of $1250 \mathrm{~V} / \mathrm{cm}$ and $80 \mu \mathrm{s}$. Fusion was assessed after $30 \mathrm{~min}$, and unfused couplets were re-pulsed. Fused couplets were placed in $10 \mu \mathrm{M} \mathrm{Ca}{ }^{2+}$-ionophore in protein-free hSOF for $5 \mathrm{~min}$, before incubation in $2 \mathrm{mM}$ 6-DMAP for a minimum of $2 \mathrm{~h}$. Finally, reconstructed embryos were placed in $0.6 \mathrm{ml} \mathrm{mSOF}$ overlaid with mineral oil and cultured in a humidified atmosphere of $5 \% \mathrm{O}_{2}, 5 \% \mathrm{CO}_{2}$ and $90 \% \mathrm{~N}_{2}$ at $38.5^{\circ} \mathrm{C}$.

\section{Embryo development}

Cellular cleaving was recorded on day 2 and blastocyst development on day 6. Day 7 blastocysts were recovered directly from the culture medium and fixed. Good-quality blastocysts (and a small number of compacted morulae) scheduled for collection on days 9-19 were vitrified on day 6 by the open pulled straw method (Vajta et al. 1996). These embryos were subsequently transferred to synchronized recipients $(n=20)$ after thawing. Only embryos without apparent cell lysis in the inner cell mass and presenting a reformed blastocoele cavity were transferred. Up to 24 blastocysts were transferred per ewe, except for ewes designated for recovery on days 17 and 19, where only up to nine embryos were transferred. Embryos were recovered from recipients on days 9, 11, 13, 17 and 19 and fixed.

\section{Embryo fixation and processing}

After recovery, embryos were fixed for either TEM or immunohistochemistry. For TEM, embryos were fixed in $3 \%$ glutaraldehyde in $0.1 \mathrm{M}$ sodium phosphate buffer $(\mathrm{PB}$, $\mathrm{pH}$ 7.2) for $1 \mathrm{~h}$ at $4{ }^{\circ} \mathrm{C}$, and then transferred to $0.1 \mathrm{M} \mathrm{PB}$ and transported from Australia to Denmark in 0.1 M PB with $3 \mathrm{mg} / \mathrm{ml}$ polyvinyl alcohol (PVA). Post-fixation took place in $1 \% \quad 0.1 \mathrm{M}$ PB followed by dehydration and embedding in Epon (Hyttel \& Madsen 1987). Embryos for immunohistochemistry were fixed in $4 \%$ paraformaldehyde (PFA) in $0.1 \mathrm{M} \mathrm{PB}(\mathrm{pH} 7.2)$ for $1 \mathrm{~h}$ at $4{ }^{\circ} \mathrm{C}$ and then transferred to $1 \%$ PFA in $0.05 \mathrm{M}$ PB. Embryos were transported in $1 \%$ PFA before dehydration and embedding.

After initial fixation, embryos were submitted to stereomicroscopy and digital image processing. A total of 52 in vivo, 38 IVC and 62 SCNT embryos were analysed in this way (Table 1). Subsequently, the embryos or parts thereof, including the embryo proper, were embedded in agar blocks for further processing. When only the embryo proper was processed, the material was orientated in the blocks to produce sagittal sections through the embryo proper. Days 7, 9, 11 and 13 embryos were submitted to sectioning and further analysis.

\section{Transmission electron microscopy (TEM)}

Epon-embedded embryos were serially cut into semi-thin sections $(2 \mu \mathrm{m})$ that were stained with $1 \%(\mathrm{w} / \mathrm{v})$ toluidin 
Table 1 Embryo diameter and length, length of embryonic disc, length of embryo proper, width of allantois and number of somites in ovine in vivo, IVC and SCNT embryos at different stages of development. Data on hatching status are also shown for days 7 and 9 . Figures are indicated as mean \pm S.D. Figures with different superscripts within rows are significantly different $(P<0.05$, Student's $t$-test on mean value).

\begin{tabular}{|c|c|c|c|}
\hline & In vivo & IVC & SCNT \\
\hline \multicolumn{4}{|l|}{ Day 7} \\
\hline Number & 6 & 6 & 8 \\
\hline Diameter, embryo $(\mu \mathrm{m})$ & $318 \pm 55^{\mathrm{a}_{*}}$ & $344 \pm 97^{\mathrm{a}_{*}}$ & $160 \pm 7^{b_{*}}$ \\
\hline Zona pellucida intact (number) & 0 & 1 & 6 \\
\hline Hatching (number) & 1 & 4 & 1 \\
\hline Hatched (number) & 5 & 1 & 1 \\
\hline \multicolumn{4}{|l|}{ Day 9} \\
\hline Number & 6 & 7 & 6 \\
\hline Diameter, embryo $(\mu \mathrm{m})$ & $950 \pm 314^{\mathrm{a}_{* *}}$ & $433 \pm 172^{b_{* *}}$ & $175 \pm 50^{b_{* *}}$ \\
\hline Zona pellucida intact (number) & 0 & 1 & 1 \\
\hline Hatching (number) & 0 & 0 & 3 \\
\hline Hatched (number) & 6 & 6 & 2 \\
\hline \multicolumn{4}{|l|}{ Day 11} \\
\hline Number & 6 & 6 & 13 \\
\hline Length, embryo $(\mathrm{mm})$ & $2.7 \pm 0.6^{\mathrm{a}}$ & $2.9 \pm 1.3^{\mathrm{a}}$ & $0.8 \pm 0.3^{b}$ \\
\hline Width, embryonic disc ( $\mu \mathrm{m})$ & $328 \pm 79^{\mathrm{a}}$ & $214 \pm 50^{\mathrm{b}}$ & $120 \pm 17^{c}$ \\
\hline \multicolumn{4}{|l|}{ Day 13} \\
\hline Number & 9 & 6 & 13 \\
\hline Length, embryo (mm) & $46.3 \pm 16.9^{\mathrm{a}}$ & $38.1 \pm 14.3^{\mathrm{a}}$ & $2.8 \pm 3.2^{\mathrm{b}}$ \\
\hline Width, embryonic disc $(\mu \mathrm{m})$ & $962 \pm 236^{a}$ & $798 \pm 291^{\mathrm{a}}$ & $293 \pm 172^{b}$ \\
\hline \multicolumn{4}{|l|}{ Day 17} \\
\hline Number & 14 & 5 & 10 \\
\hline Length, embryo proper (mm) & $6.20 \pm 0.7^{a}$ & $5.6 \pm 2.0^{\mathrm{a}}$ & $5.6 \pm 1.0^{\mathrm{a}}$ \\
\hline Width, allantos (mm) & $9.3 \pm 5.2^{\mathrm{a}}$ & $6.7 \pm 7.0^{\mathrm{ab}}$ & $3.8 \pm 1.7^{\mathrm{b}}$ \\
\hline Somites (number) & $19.1 \pm 3.8^{\mathrm{a}}$ & $14.2 \pm 3.6^{\mathrm{b}}$ & $13.3 \pm 3.1^{\mathrm{b}}$ \\
\hline \multicolumn{4}{|l|}{ Day 19} \\
\hline Number & 11 & 8 & 12 \\
\hline Length, embryo proper (mm) & $11.5 \pm 1.8^{\mathrm{a}}$ & $6.7 \pm 1.3^{\mathrm{b}}$ & $7.3 \pm 1.6^{\mathrm{b}}$ \\
\hline Width, allantois $(\mathrm{mm})$ & $70.6 \pm 21.9^{\mathrm{a}}$ & $12.3 \pm 5.0^{\mathrm{b}}$ & $13.7 \pm 7.8^{b}$ \\
\hline Somites (number) & $27.8 \pm 3.4^{\mathrm{a}}$ & $21.4 \pm 0.9^{b}$ & $22.5 \pm 4.2^{\mathrm{b}}$ \\
\hline
\end{tabular}

* Figures based on zona pellucida intact and hatched, but not hatching embryos.

** Figures based on hatched embryos.

blue and analysed by bright-field light microscopy (LM). A total of 41 embryos were analysed; 11 in vivo, 12 IVC and 19 SCNT embryos. Selected sections were re-embedded in Epon (Hyttel \& Madsen 1987), cut into ultrathin sections $(70 \mathrm{~nm})$ and stained with uranyl-acetate/lead citrate. TEM was performed on a Phillips CM100 transmission electron microscope, and digital image processing was applied.

\section{Immunohistochemistry}

Serial sections $(4 \mu \mathrm{m})$ of each embryo were cut. Selected sections were stained with haematoxylin-eosin and examined by LM for evaluation and orientation. A total of 51 paraffin-wax-embedded embryos were evaluated. Of these, 17 in vivo, 13 IVC and 20 SCNT embryos were selected for immunohistochemistry (Table 2). Remaining sections were kept at $4{ }^{\circ} \mathrm{C}$ until further use.

Consecutive paraffin sections were labelled with two immunohistochemical markers to visualize germ layer formation (Maddox-Hyttel et al. 2003). The chosen primary antibodies were rabbit polyclonal anti-human alpha-1fetoprotein for potential endoderm and monoclonal mouse anti-human vimentin for potential mesoderm. Sections were collected on Super Frost ++ slides
(Mentzel GmbH + Co KG, Braunscweigh, Germany) and allowed to adhere overnight, before being dewaxed and rehydrated. Subsequently, the slides were submitted to antigen retrieval by microwave treatment $(3 \times 5 \mathrm{~min})$ in sodium citrate buffer (0.01 M; pH 6.0). Endogenous peroxidase activity was blocked by $3 \%(\mathrm{v} / \mathrm{v}) \mathrm{H}_{2} \mathrm{O}_{2}$ in

Table 2 Numbers of in vivo, IVC and SCNT embryos presenting cells with positive staining for alpha-1-fetoprotein and vimentin at different stages of development. Total number of analysed embryos is indicated in parentheses.

\begin{tabular}{llll}
\hline & In vivo & IVC & SCNT \\
\hline $\begin{array}{llll}\text { Day 7 } \\
\quad \text { Alpha-fetoprotein }\end{array}$ & $0(4)$ & $0(3)$ & $0(4)$ \\
$\quad$ Vimentin & $0(4)$ & $0(3)$ & $0(4)$ \\
$\begin{array}{l}\text { Day 9 } \\
\text { Alpha-fetoprotein }\end{array}$ & $0(3)$ & $0(4)$ & $0(2)$ \\
$\quad$ Vimentin & $0(3)$ & $0(3)$ & $0(2)$ \\
$\begin{array}{l}\text { Day 11 } \\
\quad \text { Alpha-fetoprotein }\end{array}$ & $1(5)$ & $0(3)$ & $0(8)$ \\
$\quad$ Vimentin & $1(4)$ & $1(3)$ & $1(7)$ \\
$\begin{array}{l}\text { Day 13 } \\
\quad \text { Alpha-fetoprotein }\end{array}$ & $2(4)$ & $2(3)$ & $0(6)$ \\
$\quad$ Vimentin & $5(5)$ & $3(3)$ & $3(6)$ \\
\hline
\end{tabular}


methanol, and non-specific binding of antibodies was avoided by protein blocking agent (protein block, DAKO, Glostrup, Denmark). Incubation with the primary antibodies was performed overnight at $4{ }^{\circ} \mathrm{C}$ (alpha-1-fetoprotein: 1:5000 (DAKO); vimentin: 1:2500 (Zymed, Carlton Court, San Francisco, USA) diluted in PBS with 1\% BSA). Throughout the procedures, negative control tissue was included with every slide and incubated overnight with non-immune sera (for alpha-1-fetoprotein: rabbit IgG (DAKO); vimentin: mouse IgG1 (DAKO)). Positive control tissue (paraffin-embedded bovine day 21 embryos (Maddox-Hyttel et al. 2003)) was included with every staining batch. The primary antibodies were visualized by DAKO $\mathrm{LSAB}+$ kit followed by AEC substrate kit (Zymed), and specimens were counterstained with Mayer's haematoxylin (1 min). Finally, the sections were mounted with DAKO permanent aqueous mountant.

\section{Results}

\section{Stereo-microscopical characterization}

The kinetics of hatching as well as measurements of embryonic diameter, embryonic length, embryonic disc length, allantois width, embryo proper length and somite numbers are presented in Table 1. In general, the embryos collected at days 7 and 9 were spherical blastocysts; day 11 embryos were larger and some clearly ovoid, whereas a combination of spherical, ovoid and tubular embryos was collected on day 13 . In the ovoid and tubular embryos, an embryonic disc (ED) could, in most instances, be identified. On days 17 and 19, all analysed embryos displayed a clearly identifiable embryo proper.

The IVC embryos and, in particular, the SCNT embryos were slower in hatching than the in vivo embryos (Table 1). At day 7 , the diameter of the SCNT embryos was significantly smaller than that of the in vivo and IVC embryos (Fig. 1), whereas at day 9, both the hatched SCNT and IVC embryos were smaller than the hatched in vivo embryos. At day 13, the SCNT embryos were shorter than the IVC and in vivo embryos, and there was an associated reduction in the size of their ED (Fig. 2). At day 17, no significant differences between the three groups of embryos were noted with respect to the length of the embryo proper. However, the width of the allantois as well as the number of somites was greater in the in vivo embryos than in the IVC and SCNT embryos. At day 19, the length of the embryo proper, the width of the allantois and the number of somites were greater in in vivo embryos than in IVC and SCNT embryos (Fig. 3).

\section{General morphology}

The general morphological description is based on evaluation of paraffin and Epon sections by bright-field light microscopy and of Epon sections by TEM.

At day 7 , five of six in vivo embryos presented a welldefined inner cell mass (ICM), and three had initiated the
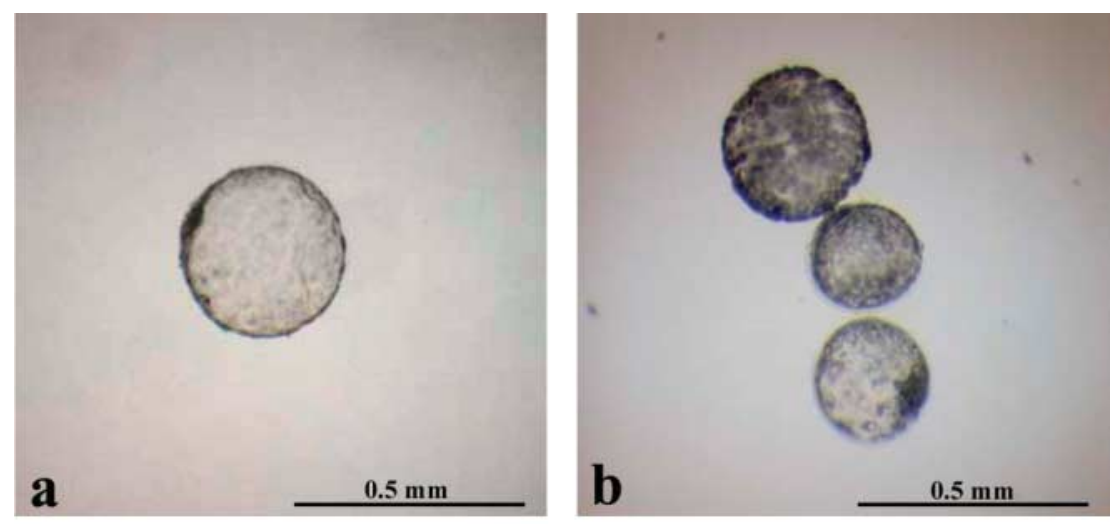

Figure 1 Stereo-micrographs of typical day-7 embryos. (a) In vivo embryo devoid of a zona pellucida. (b) IVC embryos, two of which are devoid of their zona pellucida. Note the darker appearance of these embryos compared with ' $a$ '. (c) SCNT embryos, some of which are in the process of hatching. 

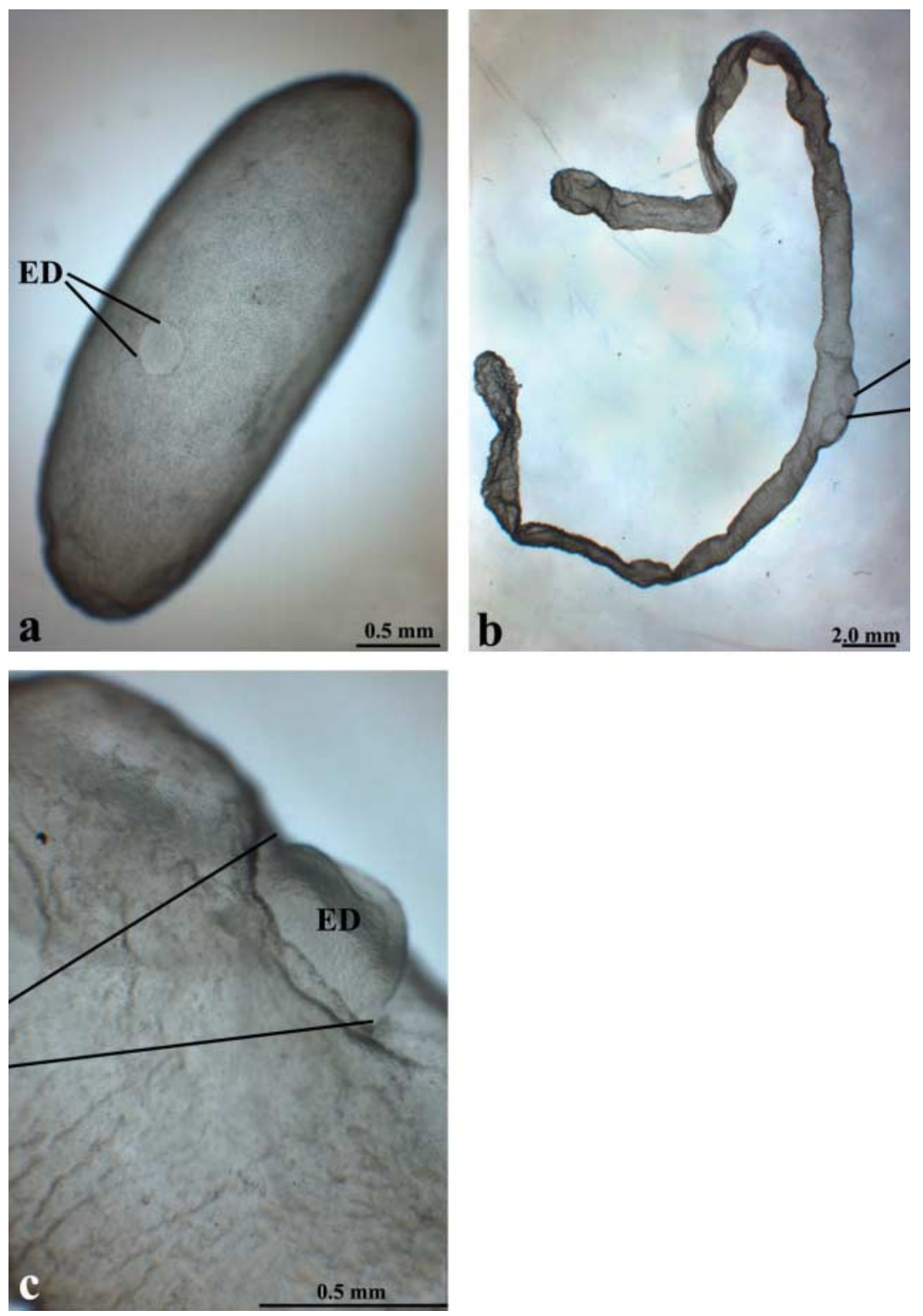

Figure 2 Stereo-micrographs of day-11 and day13 in vivo embryos, illustrating size and stage of development. (a) Ovoid day-11 embryo during initial elongation. The embryonic disc (ED) is clearly visible. (b) Elongated day-13 embryo with prominent, protruding embryonic disc (c).

formation of the hypoblast (Fig. 4). Consequently, the remaining cells of the ICM are referred to as the epiblast. The hypoblast initially appeared directly beneath the epiblast and proceeded along the inside of the trophoblast, but none of the embryos had a complete hypoblast lining. At the ultrastructural level, the epiblast cells were uniform and rounded, presenting large nuclei and prominent nucleoli and a cytoplasm dominated by mitochondria, polyribosomes and lipid droplets. The hypoblast cells were squamous and linked by tight junctions. The trophectoderm cells were particularly rich in intermediate filaments, some of which engaged in the formation of desmosomes, along with which tight junctions were noted.

Among the IVC embryos, four of six presented a welldefined ICM, and three of these had initiated hypoblast formation. In two embryos, no ICM or epiblast was ident- ified, although an incomplete hypoblast was observed in one. Cellular debris was noted in the perivitelline space of unhatched and hatching embryos. Only one of eight SCNT embryos presented a well-defined ICM and epiblast. This embryo displayed initial formation of the hypoblast; this, however, was also noted in another embryo in which no epiblast was identified. In the unhatched and hatching embryos, abundant accumulations of cellular debris in the peri-vitelline space was evident (Fig. 4).

At day 9, four of six in vivo embryos presented a welldefined epiblast. All in vivo embryos had a complete hypoblast lining the inside of the trophoblast; in two embryos, the hypoblast directly beneath the epiblast had assumed a more cuboidal appearance. At the ultrastructural level, Rauber's layer, while still intact, appeared as a thin layer of cytoplasmic trophectoderm processes. 

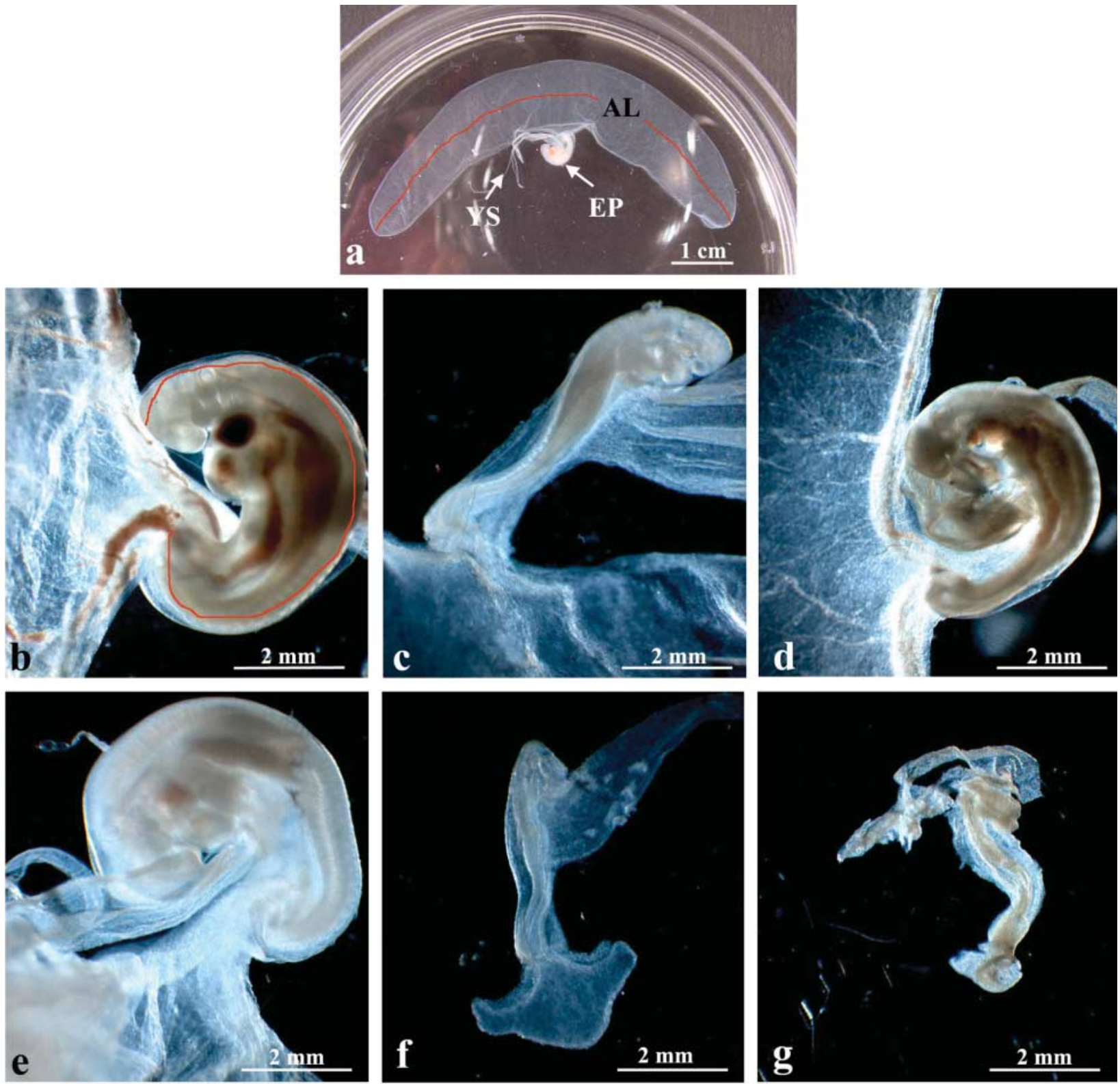

Figure 3 Stereo-micrographs of day-19 embryos. (a) In vivo embryo. The red line illustrates the measurement of the allantois (AL). Note the embryo proper (EP) and the rudimentary yolk sack (YS). The largest of the day-19 embryos: in vivo embryo (b), IVC embryo (c) and (d) SCNT embryo. The red line illustrates the measurement of the embryo proper. The smallest of the day-19 embryos: (e) in vivo embryo, (f) IVC embryo and (g) SCNT embryo.

In four of seven IVC embryos, a well-defined ICM or epiblast was found, while six embryos presented a complete hypoblast. At the ultrastructural level, IVC embryos displayed features comparable with day 7 in vivo embryos. Only one of the six SCNT-embryos presented a well-defined ICM or epiblast. This embryo also had an incomplete hypoblast. A complete and an incomplete hypoblast were, however, also noted in two embryos without an apparent epiblast.

At day 11, five of six in vivo embryos presented a welldefined ED consisting of an apparently pseudostratified or, in some regions, bilayered epiblast with its underlying hypoblast (Fig. 5). The hypoblast extended into a complete lining of the trophectoderm. Evidence of mitotic activity was observed primarily in the upper layer of the epiblast, and dome-shaped epiblast protrusions were seen at the apical epiblast surface. The hypoblast cells directly beneath the epiblast were cuboidal. At the ultrastructural level, the epiblast cells appeared to have formed a welldefined superficial layer of cells that displayed microvilli and were connected by putative tight junctions (Fig. 6). Intercellular junctions were not observed elsewhere in the 


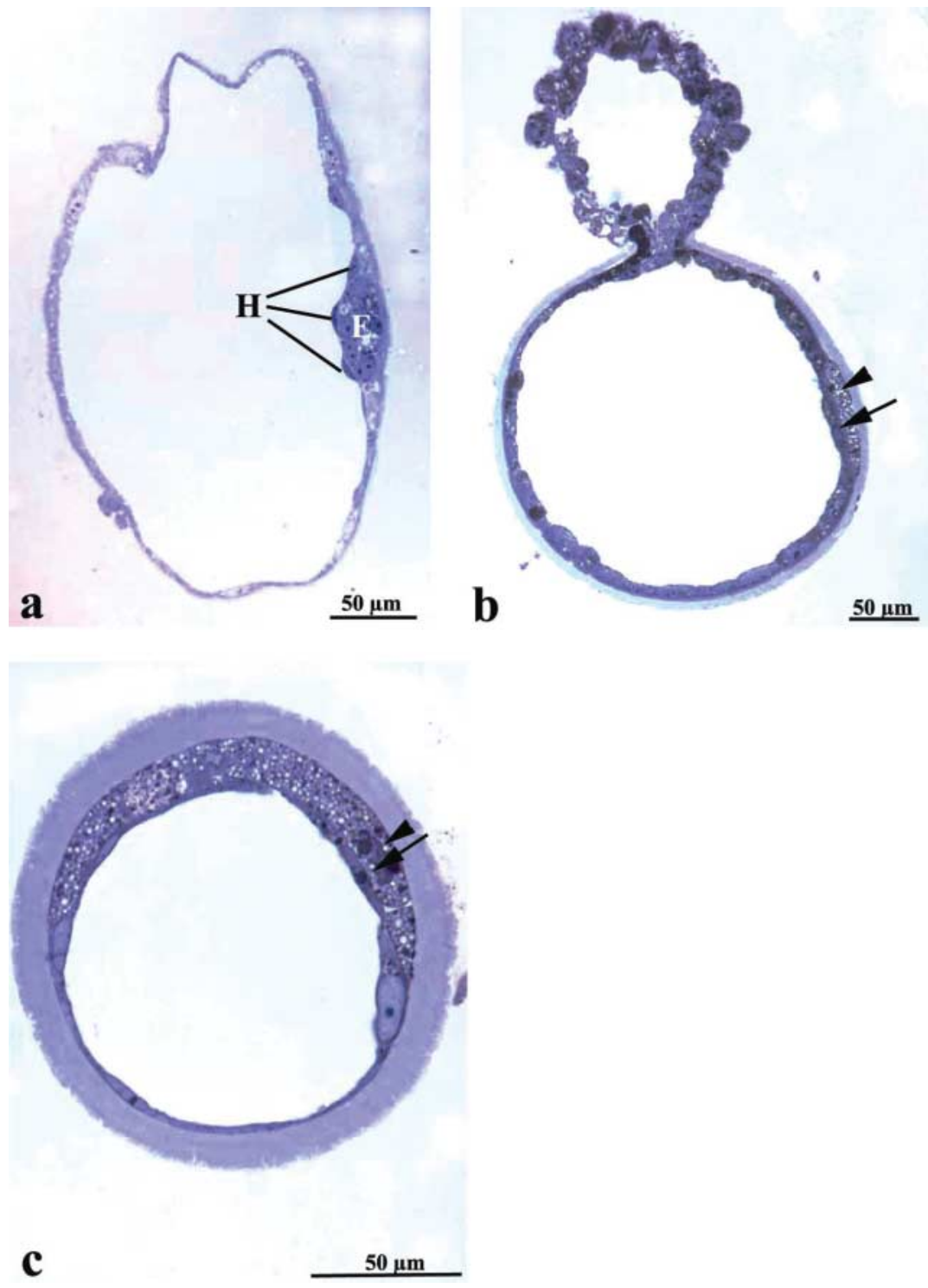

Figure 4 Light micrographs of typical day-7 embryos. (a) In vivo embryo showing a welldefined epiblast (E) and a developing hypoblast (H). (b) IVC embryo in the process of hatching. Note the debris in the perivitelline space (arrowhead) peripheral to the trophectoderm (arrow). (c) SCNT embryo with intact zona pellucida. Note the abundant debris in the perivitelline space (arrowhead) peripheral to the trophoblast (arrow). epiblast. At the transition from superficial epiblast to trophectoderm, putative tight junctions were observed between these two cell types. In three embryos, evidence of initial gastrulation appeared as a single cluster or small clusters of cells in the space between the epiblast and hypoblast. These putative endoderm and mesoderm precursor cells were rounded or slightly cuboidal and presented a large nucleus, prominent nucleoli and mitochondria as dominant features. The precursor cells made contact to each other through short cytoplasmic processes.

All the six IVC embryos presented a smaller but welldefined ED and a complete hypoblast, whereas initial gastrulation was not yet evident (Fig. 5). Signs of a pseudostratified or bilayered organization of the epiblast were noted in only three of six IVC embryos. In seven of 13 SCNT embryos, an epiblast was found together with a complete hypoblast, but signs of a pseudostratified or bilayered organization of the epiblast were evident in only a single embryo. Among the six embryos without an ICM or epiblast, five presented a complete hypoblast. At the ultrastructural level, the epiblast of the SCNT embryos resembled the earlier (day 9) in vivo epiblasts. Remnants of Rauber's layer were seen frequently along the surface of the apical epiblast. The hypoblast cells directly beneath the epiblast were not as cuboidal or as closely apposed as in the in vivo and IVC embryos, and initial gastrulation was not observed in any of the SCNT embryos.

At day 13, all nine in vivo embryos displayed a welldefined ED presenting a well-developed ectoderm and endoderm as well as mesoderm, of which the extraembryonic parts were clearly divided into visceral and somatic portions (Fig. 7). The upper ectoderm cells presented marked dome-shaped protrusions and numerous 

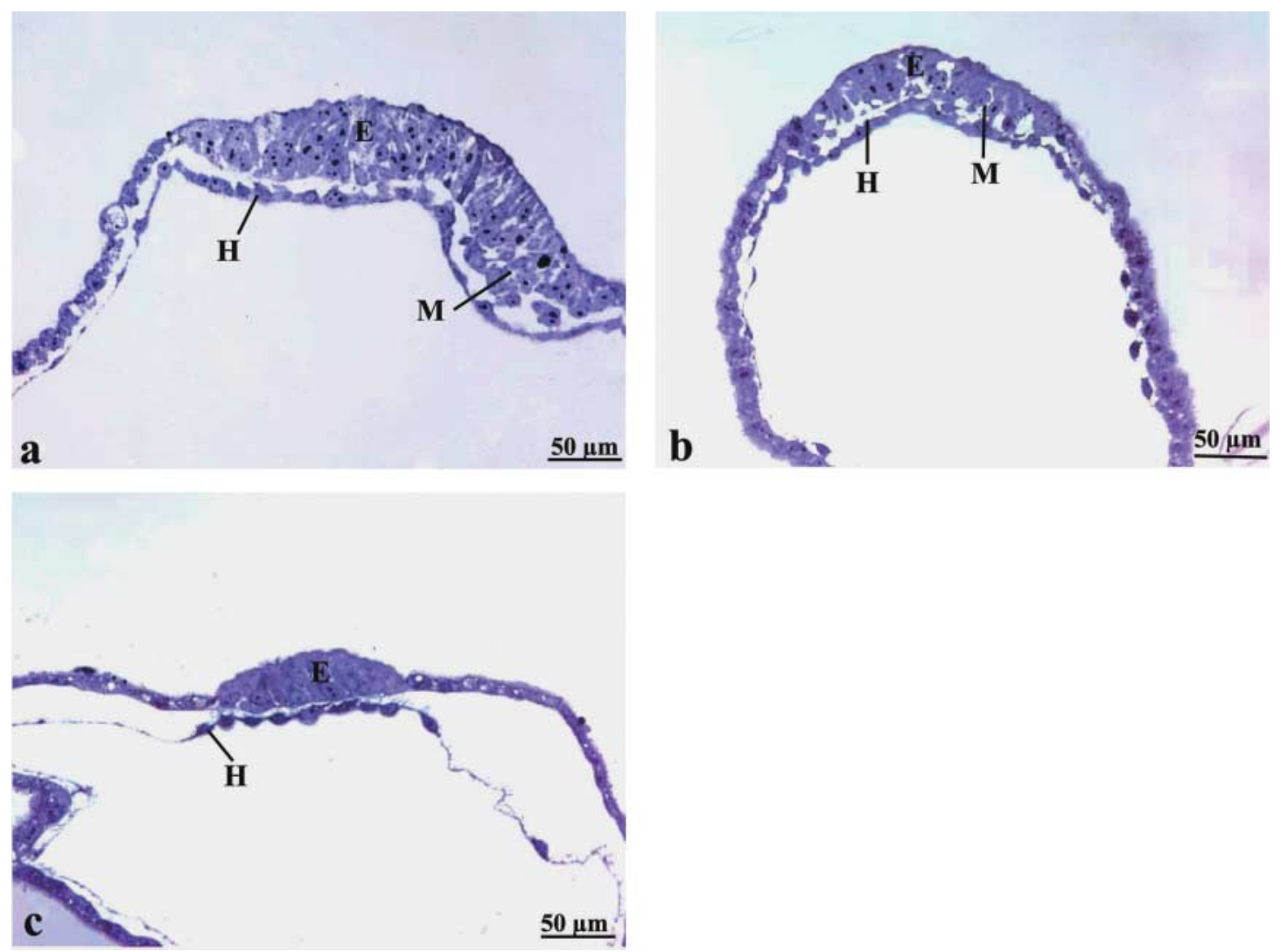

Figure 5 Light micrographs of typical day-11 embryos. (a) In vivo embryo showing large, well-defined epiblast (E) with underlying hypoblast (H). Note the pseudostratified organization of the epiblast and the initial development of mesoderm $(\mathrm{M})$ in the space between epiblast and hypoblast. (b) IVC embryo showing a smaller but still well-defined epiblast (E) and a complete hypoblast (H). Signs of initial mesoderm (M) formation are noted. (c) SCNT embryo displaying a small but well-defined epiblast (E). A complete hypoblast $(\mathrm{H})$, but no mesoderm formation is noted.
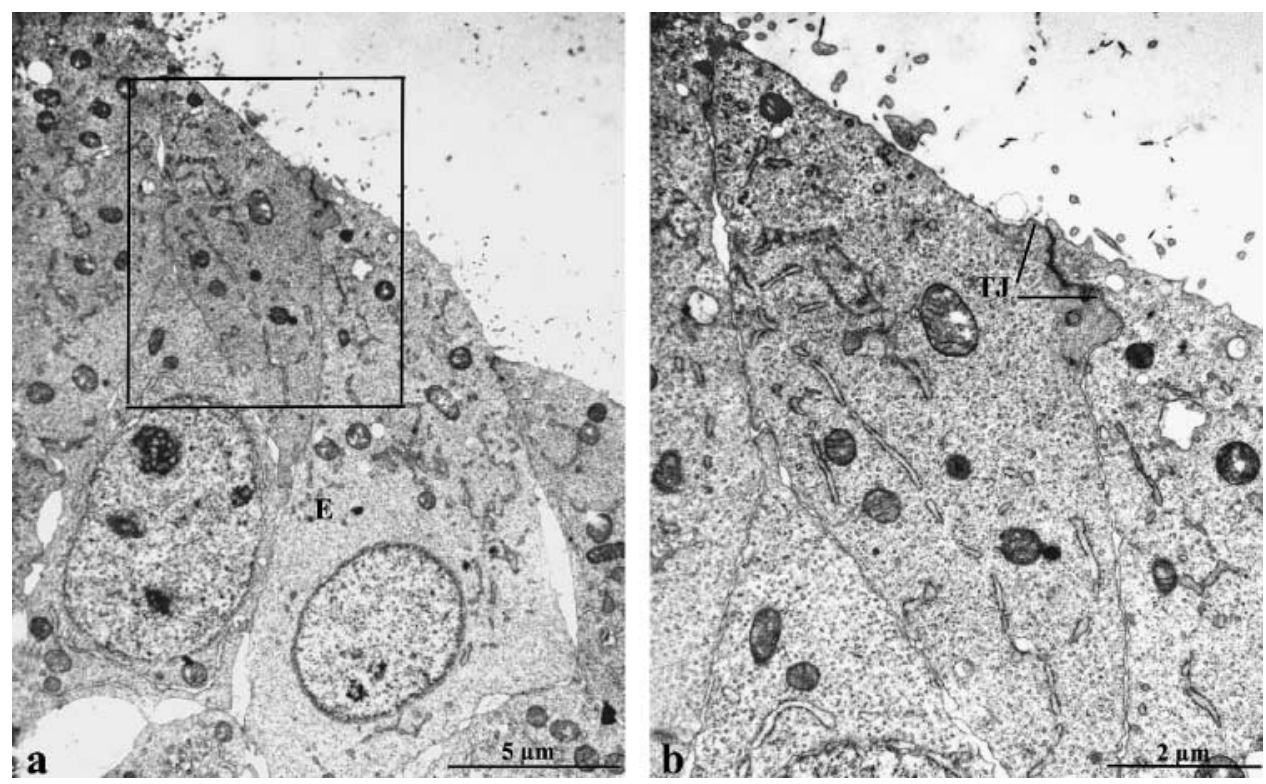

Figure 6 Transmission electron micrographs from the superficial portion of the epiblast in day-11 in vivo embryo. (a) The superficial epiblast cells (E) form a tight layer. (b) Detail of framed section in (a) enlarged. Adjacent epiblast cells are connected by putative tight junctions (TJ). 
mitoses. In three embryos, amniotic folds were present as uni- or bilaterally trophectoderm upfoldings in close proximity to the ectoderm. At the ultrastructural level, the ectoderm cells resembled their epiblast precursors on day 11 in vivo embryos. Again, mesoderm cells made contact with each other through cytoplasmic processes.

All IVC embryos had a clearly identifiable ED and all displayed endoderm and mesoderm formation, but visceral and somatic components of the latter were only clearly evident in two of six embryos. No evidence of amniotic folds was seen. In nine of 13 SCNT embryos, a clearly identifiable ED was observed. In six embryos, initial gastrulation was noted, but none had progressed to form visceral and somatic mesoderm, or had initiated amnion formation.

\section{Immunohistochemistry}

Immunohistochemical staining was performed on paraffin sections for alpha-1-fetoprotein and vimentin (Table 2).

\section{Alpha-1-fetoprotein}

Staining was confined to the cytoplasm of hypoblast cells. Weak staining was observed in a single, day-11 in vivo embryo. Evident staining was seen in in vivo and IVC embryos on day 13, whereas none of the SCNT embryos exhibited staining.

\section{Vimentin}

All in vivo embryos displayed a positive cytoplasmic staining for vimentin in the ventral part of the epiblast/ectoderm and in all components of the mesoderm on day 13 (Fig. 8). A single embryo, without evidence of gastrulation, showed staining in the ventral portion of the epiblast on day 11. All IVC embryos displayed staining of the ventral epiblast/ectoderm on day 13 and, if present, in the mesoderm. On day 11, one of three embryos stained positive in the ventral portion of the epiblast. Among the SCNT embryos, three of six day-13 embryos showed positive staining of a few cells in the ventral parts of the epiblast (Fig. 8). Similar staining was noted in a single embryo on day 11 .

\section{Discussion}

In the present study, both pre- and peri-implantation development of the manipulated (IVC and SCNT) sheep embryos was assessed. In vivo embryos were used as a control. IVC embryos were cultured in a medium sup- plemented with 20\% human serum in order to provoke embryonic stress leading to LOS changes (Thompson et al. 1995, Walker et al. 1996a).

The stereo-microscopic measurements clearly showed that in vivo embryos, with respect to the size of the embryo, the length and development of the embryo proper, and the size of the allantois, consistently developed at a faster rate than SCNT embryos and, to a lesser degree, IVC embryos. The magnitude of this effect is probably even more pronounced than what appears from the presented data, as embryos that were most impaired after the period of in vivo development in the recipient were potentially eliminated from the IVC and SCNT groups. Moreover, the variation in developmental measures was much more pronounced among IVC embryos and, in particular, SCNT embryos than among their in vivo counterparts, a phenomenon that would render only the most advanced IVC and SCNT individuals likely to continue development to term (Holm et al. 1996, Koo et al. 2002). Sheep embryos containing low cell numbers have been shown to display decreased survival rates and increased sensitivity to asynchrony in the uterine environment (Willadsen 1981). Furthermore, the degree of DNA fragmentation is increased in SCNT embryos, mainly in the ICM cells, indicating that SCNT embryos with low cell numbers have a higher rate of apoptosis (Fahrudin et al. 2002). Both the increased variation in embryo size and observed delay in development could thus be expected to have damaging effects on the continued embryonic growth of the IVC embryos and, particularly, the SCNT embryos.

During the pre- and peri-implantation development, embryos of the large domestic species undergo three sequential rounds of differentiation where cells are recruited from an initially totipotent but, later, pluripotent cell population. At the first round of differentiation, the terminally differentiated trophoblast and the pluripotent ICM are formed, while the second round of differentiation results in delamination of the hypoblast from the ICM, a process after which the latter cell population remains pluripotent and is referred to as the epiblast. Gastrulation represents the third round of differentiation where the basic germ layers are formed by a complex process including establishment of the primitive streak and involution of cells serving as precursors of endoderm and mesoderm. The endoderm cells are inserted into the upper portion of the hypoblast lining, whereas the mesoderm develops into embryonic and extra-embryonic portions, of which the latter was divided into somatic and visceral parts. Marked differences between the three different groups of embryos were noted with respect to the differentiation of the ICM

Figure 7 Light micrographs of typical day-13 in vivo and SCNT embryos. (a) In vivo embryo displaying organization of the trophectoderm (Te), ectoderm (Ec), endoderm (En) and mesoderm, of which the extra-embryonic portion is organized into somatic mesoderm (SM) and visceral mesoderm (VM). (b) Detail from (a) showing the multilayered ectoderm (Ec), the mesoderm (M) and the endoderm (En). (c) SCNT embryo displaying involution of cells from the epiblast (E) for mesoderm (M) and putative endoderm (En) formation. (d) Detail from (c) showing the epiblast (E), mesoderm, (M) and putative endoderm (En). 

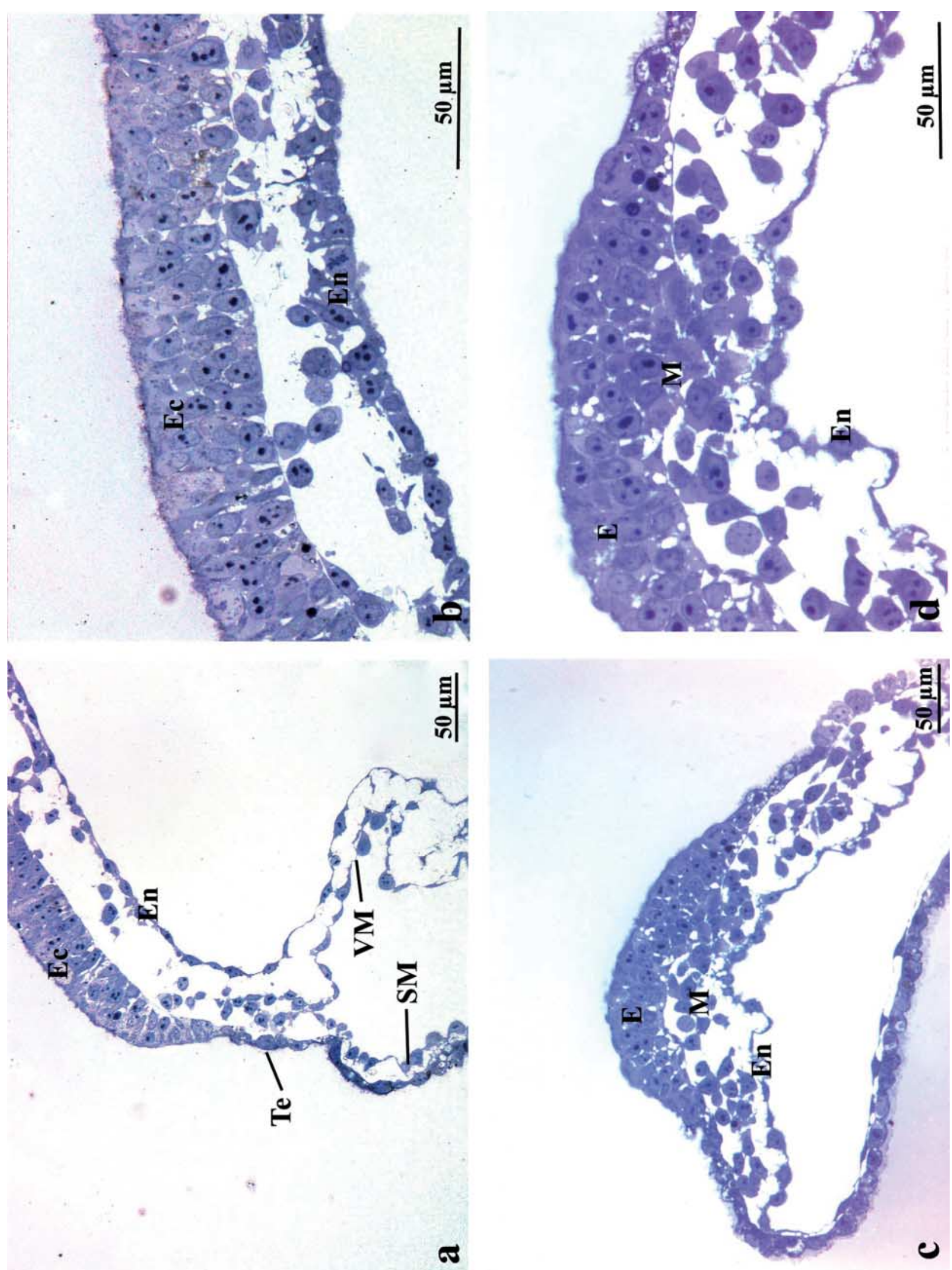

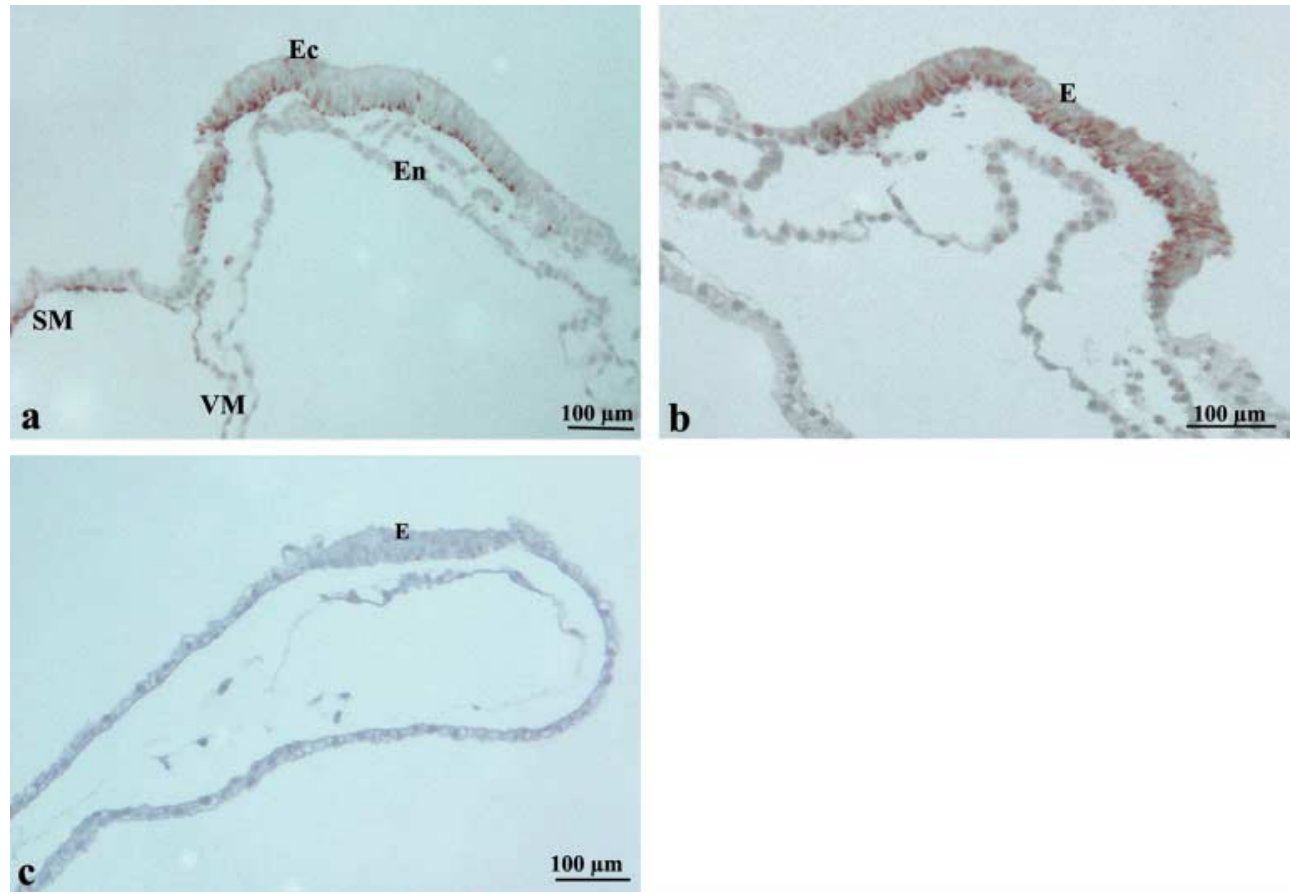

Figure 8 Light micrographs of vimentin-stained, day-13 embryos. (a) In vivo embryo displaying positive staining in the ventral portion of the ectoderm $(\mathrm{Ec})$ and in the somatic (SM) and visceral mesoderm (VM), whereas the endoderm (En) is unstained. (b) IVC embryo displaying positive staining of the ventral portion of the epiblast (E). (c) SCNT embryo displaying weak positive staining in only a few epiblast cells (E). into hypoblast and epiblast, particularly in the timing of this event. On day 7, hypoblast and epiblast were seen in all three groups of embryos, though at a higher frequency among the in vivo embryos. On day 9, all in vivo embryos and most of the IVC embryos had formed a complete hypoblast, which was, on the other hand, observed in only a single SCNT embryo. Interestingly, this embryo did not possess a recognizable epiblast. This was also noted in several of the IVC and SCNT embryos on days 9 and 11 respectively. As the hypoblast is formed by the delamination of ICM cells (Wintenberger-Torrès \& Fléchon 1974, Maddox-Hyttel et al. 2003), it seems likely that, in some cases, the formation of the hypoblast consumes the complete cell population contained in the ICM. This observation renders hypoblast formation a predominant event in the developing blastocyst. A proportion of the IVC embryos and, in particular, the SCNT embryos also lacked an identifiable ICM before the differentiation into hypoblast and epiblast. Such embryos have probably been impaired even earlier and may have contained sufficient viable cells only to form the trophoblast during the first round of differentiation. The presence of a functional ICM would not have been easily recognized before transfer (van Soom et al. 1997, McEvoy et al. 2000), and hatching of blastocysts devoid of an evident ICM has been reported in cattle (Avery et al. 1995). Thus, trophoblast differentiation may be a developmental event similar in predominance to hypoblast formation. Such so-called trophoblastic vesicles have experimentally been shown to be capable of maintaining intrauterine growth and elongation in the sheep, thus enabling the persistence of such vesicles (Heyman et al. 1984, Fléchon et al. 1986).
Large differences were noted between the experimental groups with respect to the process of gastrulation. In half of the in vivo embryos, initial gastrulation was noted on day 11 , whereas this event was only in its very early beginning in a single IVC embryo and was not seen at all in SCNT embryos. In agreement with earlier findings in the sheep (Guillomot et al. 2004), mesoderm and endoderm precursors were present before any morphological evidence of primitive streak formation. Gastrulation is preceded by the formation of a pseudostratified or bilayered organization of the epiblast, as has earlier been reported in farm animals (Betteridge \& Fléchon 1988, Flechon et al. 2004), a phenomenon which was, in general, delayed by approximately 2 days in IVC embryos and, in particular, SCNT embryos. When the timing of gastrulation was assessed with immunohistochemical markers, a similar delay was observed, especially in SCNT embryos.

IVC and SCNT embryos also displayed delay with respect to the formation of the extra-embryonic membranes, including the amnion and the allantois, which are crucial for continued development. In the large domestic species, the amnion is formed by budding of the trophoblast into chorionic folds (Bryden et al. 1972, MaddoxHyttel et al. 2003). This process was initiated in half of the in vivo embryos on day 13 , whereas none of the IVC and SCNT embryos exhibited amniotic folds. Allantois formation marks an important stage of development when the embryonic portion of the future chorioallantoic placenta is prepared. On day 17 , but particularly on day 19 , the width of the allantoic bud was greater in in vivo embryos than among their IVC and SCNT counterparts. Placental formation is a process demanding a certain synchrony between embryonic (the allantois and associated 
vascularization) and maternal (the endometrium) components, and the impaired allantoic development may well form the basis of the placental deviations noted later during SCNT-based gestation (Hill et al. 1999, Heyman et al. 2002). Furthermore, a deviant placenta could cause perinatal deaths in SCNT offspring brought to term (Chavatte-Palmer et al. 2004).

In conclusion, SCNT and IVC embryos develop slower than in vivo embryos, a phenomenon that may have detrimental effects on placentation, thus partly explaining why high embryo and fetal loss is associated with these techniques.

\section{Acknowledgements}

We thank Ms Hanne Holm and Jytte Nielsen, of the Royal Veterinary and Agricultural University, Frederiksberg, Denmark, for their outstanding assistance in the preparation and processing of the embryos, and Louise Engberg, DVM, and Camilla Rasmussen, DVM, for their precise stereo-microscopical classifications. The authors declare that there is no conflict of interest that would prejudice the impartiality of this scientific work.

\section{References}

Avery B, Brandenhoff HR \& Greve T 1995 Development of in vitro matured and fertilized bovine embryos, cultured from days 1-5 post insemination in either Menezo-B2 medium or in Hemc-6 medium. Theriogenology 44 935-945.

Bertolini M \& Anderson GB 2002 The placenta as a contributor to production of large calves. Theriogenology 57 181-187.

Betteridge KJ \& Fléchon J-E 1988 The anatomy and physiology of pre-attachment bovine embryos. Theriogenology 29 155-187.

Bryden MM, Evans HE \& Binns W 1972 Embryology of the sheep. I. Extraembryonic membranes and the development of body form. Journal of Morphology 138 169-185.

Campbell KHS, McWihr J, Ritchie WA \& Wilmut I 1996 Live lambs by nuclear transfer from an established cell line. Theriogenology 45287.

Chavatte-Palmer P, Remy D, Cordonnier N, Richard C, Issenman H, Laigre P et al. 2004 Review: health status of cloned cattle at different ages. Cloning Stem Cells 6 94-100.

Cibelli JB, Stice SL, Golueke PJ, Kane JJ, Jerry J, Blackwell C, Ponce de Leon FA \& Robl JM 1998 Cloned transgenic calves produced from nonquiescent fetal fibroblasts. Science 280 1256-1258.

Daniels R, Hall V \& Trounson AO 2000 Analysis of gene transcription in bovine nuclear transfer embryos reconstructed with granulosa cell nuclei. Biology of Reproduction 63 1034-1040.

Dean W, Santos F \& Reik W 2003 Epigenetic reprogramming in early mammalian development and following somatic nuclear transfer. Seminars in Cell and Developmental Biology 14 93-100.

de Sousa PA, King T, Harkness L, Young LE, Walker SK \& Wilmut I 2001 Evaluation of gestational deficiencies in cloned sheep fetuses and placentae. Biology of Reproduction 65 23-30.

Fahrudin M, Otoi T, Karja NW, Mori M, Murakami M \& Suzuki T 2002 Analysis of DNA fragmentation in bovine somatic nuclear transfer embryos using TUNEL. Reproduction 124 813-819.

Fléchon JE, Guillomot M, Charlier M, Fléchon B \& Martal J 1986 Experimental studies on the elongation of the ewe blastocyst. Reproduction, Nutrition, Development 26 1017-1024.

Fléchon JE, Degrouard J \& Fléchon B 2004 Gastrulation events in the prestreak pig embryo: ultrastructure and cell markers. Genesis $\mathbf{3 8}$ $13-25$.
Guillomot M, Turbe A, Hue I \& Renard JP 2004 Staging of ovine embryos and expression of the T-box genes Brachyury and Eomesodermin around gastrulation. Reproduction 127 491-501.

Han DW, Song SJ, Uhum SJ, Do JT, Kim NH, Chung KS \& Lee HT 2003 Expression of IGF2 and IGF receptor mRNA in bovine nuclear transferred embryos. Zygote 11 245-252.

Heyman Y, Camous S, Fevre J, Meziou W \& Martal J 1984 Maintenance of the corpus luteum after uterine transfer of trophoblastic vesicles to cyclic cows and ewes. Journal of Reproduction and Fertility 70 533-540.

Heyman Y, Chavatte-Palmer P, LeBourhis D, Camous S, Vignon X \& Renard JP 2002 Frequency and occurrence of late-gestation losses from cattle cloned embryos. Biology of Reproduction 66 6-13.

Hill JR, Roussel AJ, Cibelli JB, Edwards JF, Hooper NL, Miller MW et al. 1999 Clinical and pathologic features of cloned transgenic calves and fetuses (13 case studies). Theriogenology 51 1451-1465.

Hill JR, Burghardt RC, Jones K, Long CR, Looney CR, Shin T et al. 2000 Evidence for placental abnormality as the major cause of mortality in first-trimester somatic cell cloned bovine fetuses. Biology of Reproduction 63 1787-1794.

Holm P, Walker SK \& Seamark RF 1996 Embryo viability, duration of gestation and birth weight in sheep after transfer of in vitro matured and in vitro fertilized zygotes cultured in vitro or in vivo. Journal of Reproduction and Fertility 107 175-181.

Humpherys D, Eggan K, Akutsu H, Hochedlinger K, Rideout WM III, Biniszkiewicz D et al. 2001 Epigenetic instability in ES cells and cloned mice. Science 293 95-97.

Humpherys D, Eggan K, Akutsu H, Friedman A, Hochedlinger K \& Yanagimachi R et al. 2002 Abnormal gene expression in cloned mice derived from embryonic stem cell and cumulus cell nuclei. PNAS 99 12889-12894.

Hyttel P \& Madsen I 1987 Rapid method to prepare mammalian oocytes and embryos for transmission electron microscopy. Acta Anatomica (Basel) 129 12-14.

Koo DB, Kang YK, Choi YH, Park JS, Kim HN, Oh KB et al. 2002 Aberrant allocations of inner cell mass and trophectoderm cells in bovine nuclear transfer blastocysts. Biology of Reproduction 67 487-492.

Maddox-Hyttel P, Alexopoulos NI, Vajta G, Lewis I, Rogers P, Cann L et al. 2003 Immunohistochemical and ultrastructural characterization of the initial post-hatching development of bovine embryos. Reproduction 125 607-623.

McEvoy TG, Sinclair KD, Young LE, Wilmut I \& Robinson JJ 2000 Large offspring syndrome and other consequences of ruminant embryo culture in vitro: relevance to blastocyst culture in human ART. Human Fertility (Cambridge, England) 3 238-246.

Peura TT 2003 Improved in vitro development rates of sheep somatic nuclear transfer embryos by using a reverse-order zona-free cloning method. Cloning Stem Cells 5 13-24.

Shi W, Zakhartchenko V \& Wolf E 2003 Epigenetic reprogramming in mammalian nuclear transfer. Differentiation 71 91-113.

Tervit HR, Whittingham DG \& Rowson LE 1972 Successful culture in vitro of sheep and cattle ova. Journal of Reproduction and Fertility 30 493-497.

Thompson JG, Gardner DK, Pugh PA, McMillan WH \& Tervit HR 1995 Lamb birth weight is affected by culture system utilized during in vitro pre-elongation development of ovine embryos. Biology of Reproduction 53 1385-1391.

Vajta G, Holm P, Greve T \& Callesen H 1996 Factors affecting survival rates of in vitro produced bovine embryos after vitrification and direct in-straw rehydration. Animal Reproduction Science $\mathbf{4 5}$ $191-200$.

van Soom A, Ysebaert MT \& de Kruif A 1997 Relationship between timing of development, morula morphology, and cell allocation to inner cell mass and trophectoderm in in vitro-produced bovine embryos. Molecular Reproduction and Development 47 47-56.

Walker SK, Hartwich KM \& Seamark RF 1996a The production of unusually large offspring following embryo manipulation: concepts and challenges. Theriogenology 45 111-120. 
Walker SK, Hill JL, Kleemann DO \& Nancarrow CD $1996 b$ Development of ovine embryos in synthetic oviductal fluid containing amino acids at oviductal fluid concentrations. Biology of Reproduction 55 703-708.

Willadsen SM 1981 The development capacity of blastomeres from 4- and 8-cell sheep embryos. Journal of Embryology and Experimental Morphology 65 165-172.

Wilmut I, Schnieke AE, McWhir J, Kind AJ \& Campbell KH 1997 Viable offspring derived from fetal and adult mammalian cells. Nature 385 810-813.

Wilson JM, Williams JD, Bondioli KR, Looney CR, Westhusin ME \& Mccalla DF 1995 Comparison of birth-weight and growth-characteristics of bovine calves produced by nuclear transfer (cloning), embryo-transfer and natural mating. Animal Reproduction Science $3873-83$.

Wintenberger-Torrès S \& Fléchon JE 1974 Ultrastructural evolution of the trophoblast cells of the pre-implantation sheep blastocyst from day 8 to day 18. Journal of Anatomy 118 143-153.

Wrenzycki C, Wells D, Herrmann D, Miller A, Oliver J, Tervit R \& Niemann H 2001 Nuclear transfer protocol affects messenger RNA expression patterns in cloned bovine blastocysts. Biology of Reproduction 65 309-317.

Wrenzycki C, Lucas-Hahn A, Herrmann D, Lemme E, Korsawe K \& Niemann H 2002 In vitro production and nuclear transfer affect dosage compensation of the X-linked gene transcripts G6PD, PGK, and Xist in preimplantation bovine embryos. Biology of Reproduction 66 127-134.

Young LE, Sinclair KD \& Wilmut I 1998 Large offspring syndrome in cattle and sheep. Reviews of Reproduction 3 155-163.

Young LE, Fernandes K, McEvoy TG, Butterwith SC, Gutierrez CG \& Carolan C et al. 2001 Epigenetic change in IGF2R is associated with fetal overgrowth after sheep embryo culture. Nature Genetics $27153-154$

Received 18 June 2005

First decision 21 July 2005

Revised manuscript received 29 July 2005

Accepted 19 August 2005 